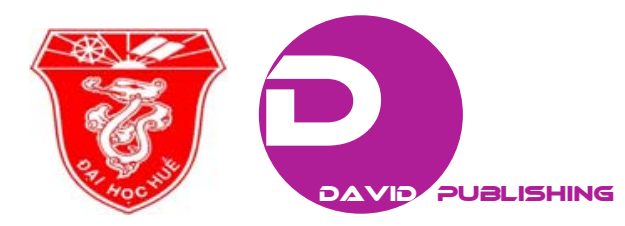

\title{
Photosynthetic Responses of Sweet Sorghum Cultivars to Cadmium Toxicity
}

\author{
Dinh Thi Thanh Tra $^{1,2}$, Hua Xiao ${ }^{1}$, Siping Zhang ${ }^{1}$, Feng Luo ${ }^{1}$, Igarashi Yasuo ${ }^{1}$ and Changzheng Xu ${ }^{1}$ \\ 1. Research Center of Bioenergy and Bioremediation, College of Resources and Environment, Southwest University, Chongqing \\ 400715, China \\ 2. Faculty of Agriculture-Forestry-Fishery, Quang Binh University, Dong Hoi City, Quang Binh Province, Vietnam
}

\begin{abstract}
Sweet sorghum is a C4 plant with high efficiency of photosynthesis and accumulation of photosynthetic products during growth stage. Until now, little is known about photosynthetic characteristics of sweet sorghum subjected to heavy metal contaminated soil. In this study, photosynthetic modification of sweet sorghum was measured in response to cadmium (Cd) under greenhouse conditions. The experiment was concentrated specifically on Keller (KE) and E-Tian (ET), two cultivars of sweet sorghum. The plants subjected to $100 \mathrm{mg} / \mathrm{kg} \mathrm{Cd}$ in soil were compared with the control plants without $\mathrm{Cd}$ treatment. The results indicated that both cultivars of sweet sorghum display similar photosynthetic responses to Cd exposure. The high Cd concentration resulted in significant decline of photosynthesis net rate (Pn). Pn of ET declines more than Cd-treated KE plants. Moreover, Cd-treated plants were detected to have lower stomata conductance (gs) and intercellular $\mathrm{CO}_{2}$ concentrations (Ci) than control plants. Chlorophyll content also displayed significant differences between control and Cd-treated plants. In ET, the reduction of both chlorophyll-a and chlorophyll-b was observed under Cd stress, compared with the controls. In contrast, chlorophyll content was significantly enhanced by Cd stress in KE. In conclusion, through the comparison between two sweet sorghum cultivars, it is demonstrated the photosynthetic activity of ET more sensitive to Cd stress than that of KE. Therefore, KE has a potential for biofuel production and phytoremediation of heavy metal in soil.
\end{abstract}

Key words: Sweet sorghum, photosynthesis, cadmium.

\section{Introduction}

Heavy metals are the main group of inorganic contaminants that seriously threaten food safety and public health. Nowadays, a large amount of land is contaminated by heavy metals due to industrial development and human activities, including fertilizers and emissions from municipal waste incinerators, car exhaust, residues from metalliferous mines and smelting industries, sludge or municipal compost and use of pesticides [1, 2]. Heavy metal contamination, such as cadmium $(\mathrm{Cd})$, lead $(\mathrm{Pb})$, copper $(\mathrm{Cu})$, zinc $(\mathrm{Zn})$ and so on, has become a public concern in the world. Among them, $\mathrm{Cd}$ is one of the most toxic and non-essential heavy metal. $\mathrm{Cd}$ can be easily absorbed by plants and accumulated in

Corresponding author: Changzheng Xu, Ph.D., research fields: bioremediation and bioenergy. agricultural products. Many methods and processes of preventing, removing and correcting the negative effects of pollutants released into the environments exist, but their application for this purpose has either been poorly implemented or not at all [3]. Thus, all major research studies ponder on the use of biological factors to deal and repair environment. Phytoremediation is defined as the use of plants to remove pollutants from the environment or to render them harmless [4].

Sorghum bicolor originated from Africa is a pro-poor multipurpose crop that provides food, feed, fiber and fuel across a range of agro-ecosystems, especially in those with fragile conditions [5]. Sorghum is classified into the following four groups by application: grain sorghum, sweet sorghum, broom sorghum and grass sorghum. Sweet sorghum is an 
important bioenergy crop, because it can produce both food and fuel, with a high photosynthetic activity and high concentration of soluble sugars in stem. Sorghum is resistant to drought, high temperature and toxic pollutants. It is able to accumulate large quantities of $\mathrm{Cd}, \mathrm{Cu}, \mathrm{Pb}$ and $\mathrm{Zn}$ in shoots, and its biomass production was higher than other energy crops biomass production [6].

Moreover, sorghum plants were highly tolerant to metal pollution and capable of reaching high biomass values in the presence of metals [7]. The effect of heavy metals $(\mathrm{Cd}, \mathrm{Pb}, \mathrm{Zn}$ and $\mathrm{Cu})$ on morphological and physiological characteristics of sorghum has been studied by Soudek et al. [6], Zhuang et al. [8] and Liu et al. [9]. They investigated the effect of $\mathrm{Cd}^{2+}$ on root activities, malondialdehyde contents in leaves, etc., at some stages of development, such as seedlings, elongation stage and so on. The results showed that low concentrations of $\mathrm{Cd}^{2+}$ stimulated the growth of sorghum plants, but high concentrations of $\mathrm{Cd}^{2+}(50$ $\mathrm{mg} / \mathrm{kg}$ and $100 \mathrm{mg} / \mathrm{kg}$ ) significantly depressed the growth of sorghum plants. Previous studies have also focused on photosynthesis response of sorghum under different watering regimes [10].

Photosynthesis is the basic process of energy and biomass production in plants [11]. However, few studies have been performed to explore the photosynthesis characteristics of sweet sorghum under $\mathrm{Cd}$ stress. In this study, the photosynthesis characteristics of two sweet sorghum cultivars were assayed to demonstrate the effect of heavy metals on the photosynthesis process, especially during the flowering and seed production period. The results would provide a theoretical basis for using sweet sorghum to produce bioenergy combined with phytoremediation for heavy metal contaminated soils.

\section{Materials and Methods}

\subsection{Plant Materials and Experimental Design}

Two lines of sweet sorghum, Keller (KE) and E-Tian (ET), were chosen as plant materials. KE
(GRIN access code PI 653617) is an elite sweet sorghum line developed by DM Broadhead at US Sugar Crops Field Station at Meridan, Mississippi in 1982, and has been grown globally and proven to have good performance across a range of environmental conditions. ET (literally meaning Russian sweet in Chinese) introduced to China in the early 1970s, is known to possess high Brix content in stem [5].

Seeds were immersed in distilled water and then germinated in the dark at $28^{\circ} \mathrm{C}$ for $5 \mathrm{~d}$. Subsequently, the seedlings were transferred to pots (diameter: 30 $\mathrm{cm}$; height: $25 \mathrm{~cm}$ ) with peat soil $(2 \mathrm{~kg}$ soil for 2 seedlings/pot) and cultivated under glasshouse conditions $\left(28-32{ }^{\circ} \mathrm{C}\right.$ with $14-16 \mathrm{~h} \mathrm{light} / 22-26{ }^{\circ} \mathrm{C}$ with $8-10 \mathrm{~h}$ dark). $\mathrm{CdCl}_{2}$ in solution was mixed with soil to increase $\mathrm{Cd}$ concentration to $100 \mathrm{ppm}$ at the eight-leaf stage for $\mathrm{Cd}$ treatment. The plants without $\mathrm{Cd}$ treatment acted as the control. The measurement of photosynthesis parameters was conducted at $75 \mathrm{~d}$ after $\mathrm{Cd}$ exposure. There are 12 biological replicates for $\mathrm{Cd}$ treatment and control.

\subsection{Photosynthesis Analysis}

CIRAS2 portable photosynthesis system (PP System company, USA) was used for the measurement of photosynthesis parameters. Two fully expanded leaves under the flag leaf of each plant were assayed (the $2 \mathrm{nd}$ leaf and $3 \mathrm{rd}$ ). The measurements ( 3 readings/leaf) were replicated on 12 plants every treatment. The net photosynthesis (Pn), intercellular $\mathrm{CO}_{2}$ concentration $(\mathrm{Ci})$, transpiration rate $(\mathrm{E})$ and stomatal conductance (gs) were determined under a light intensity of 1,200-1,600 $\mu \mathrm{mol}$ (photon) $/ \mathrm{m}^{2} / \mathrm{s}$.

Chlorophyll pigments were extracted for measurement. Leaves were cut down and immediately put into ice. Then $0.15 \mathrm{~g}$ of the sample was weighed and extracted for chlorophyll according to the method of Lichtenthaler and Wellburn [12]. A spectrophotometer (Hitachi U-3000) was then used to measure the chlorophyll pigments. 


\subsection{Data Analysis}

All the data were expressed as means \pm standard deviation (SD). Comparison of means was performed by the least significant difference (LSD) test $(P \leq 0.05)$ using Statistix software (version 10.0).

\section{Results and Discussion}

\subsection{Effect of $\mathrm{Cd}^{2+}$ on Plant Photosynthesis Parameters}

Photosynthesis is sensitive to changeable environmental conditions, and the way photosynthesis activity adapts to environments would be different in plants. Here, four parameters, including net photosysnthesis rate $(\mathrm{Pn})$, intercellular $\mathrm{CO}_{2}$ concentration $(\mathrm{Ci})$, transpiration rate $(\mathrm{E})$ and stomatal conductance (gs), were measured to characterize the Cd-induced photosynthetic changes.

In both KE and ET cultivars, Pn displayed significant differences between control and Cd-treated plants (Figs. 1a and 1b). Compared with control plants, the Pn of Cd-treated plants decreased by $5.29 \%$ to $16.7 \%$ and $27.3 \%$ to $29.4 \%$ in the 2 nd leaf and the $3 \mathrm{rd}$ leaf of KE and ET, respectively. Especially in the $3 \mathrm{rd}$ leaf, $\mathrm{Pn}$ of $\mathrm{KE}$ in control reached $5.07 \mu \mathrm{mol} / \mathrm{m}^{2} / \mathrm{s}$, while only $4.2 \mu \mathrm{mol} / \mathrm{m}^{2} / \mathrm{s}$ in Cd-treated KE plants. In ET, the inhibition of $\mathrm{Cd}$ on $\mathrm{Pn}$ was clearer. For both leaves, the net photosynthesis in the control plants was higher than the Cd-treated plants (Fig. 1).

Pn decreases with increasing concentration of $\mathrm{Cd}$ treatment, which has been reported by Liu et al. [9].

In addition, Pn of the 2nd leaf was higher than Pn of the 3rd leaf observed in both cultivars (Figs. 1a and $1 b)$, probably due to leaf senescence during growth. In this experiment, position of leaves was determined from top to bottom, therefore the 3rd leaf was older than the 2nd leaf. Senescence is a normal event in the life cycle of plants [13]. It is a sequence of complex degenerative processes that are initiated at full maturity and may ultimately lead to leaf death. The most remarkable events in leaf senescence are the loss of chlorophyll and the disassembly of the photosynthetic apparatus, which result in decreases in the photosynthetic energy conversion capacity and efficiency [14]. The result of Falqueto et al. [14] indicated that pigment content, photochemical efficiency of photosystem II and electron transport decreased significantly according to the position of leaves in two rice genotypes from the 1 st to the 4 th leaf.

Comparing the two varieties KE and ET, KE had higher Pn than ET, probably due to genotype and morphological characteristics of plant. In this experiment, it was also found that the specific leaf area (SLA) of KE was higher than of ET.

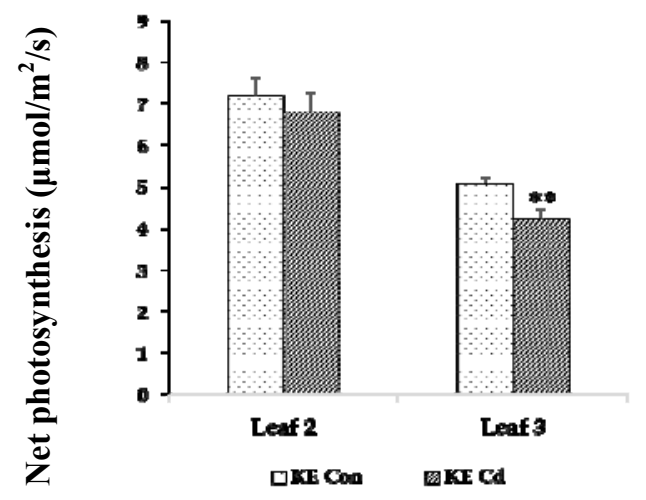

(a)

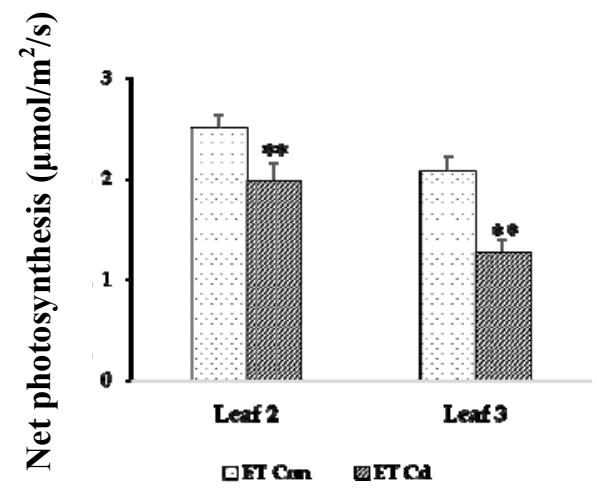

(b)

Fig. 1 Net photosynthesis (Pn, $\mu \mathrm{mol} / \mathrm{m}^{2} / \mathrm{s}$ ) of KE (a) and ET (b) under Cd stress conditions.

Data with $* *$ on the column mean significant difference at 0.05 level. 
Previous result has suggested that the photosynthesis rate may be relative with the leaf area [15]. The species with higher SLA usually show high potential relative growth rates and higher $\operatorname{Pn}[16,17]$.

Therefore, photosynthesis was inhibited by $\mathrm{Cd}$ exposure, it can be concluded that ET is more sensitive to net rate of photosynthesis changes than KE under Cd stress.

The rate of photosynthesis is an important physiological parameter, which governs the dry matter production and consequently the yield; intercellular $\mathrm{CO}_{2}$, transpiration rate and stomatal conductance play an important role in assimilation of photosynthesis [18]. The results showed no significant differences in $\mathrm{Ci}$ of the two sweet sorghum cultivars. Intercellular $\mathrm{CO}_{2}$ concentration decreased in the 2nd leaf of $\mathrm{Cd}$ plant, but was not statistically significant, in comparison to the 3rd leaf (Fig. 2a). The highest Ci (399.25 $\mu \mathrm{mol} / \mathrm{mol})$ was observed at the $3 \mathrm{rd}$ leaf of ET Cd-treated plant, while the lowest $\mathrm{Ci}(272.97$ $\mu \mathrm{mol} / \mathrm{mol}$ ) was recorded at the 2 nd leaf of $\mathrm{KE}$ Cd-treated plant (Fig. 2a). It suggests an ability of negative correlation between $\mathrm{Pn}$ and $\mathrm{Ci}$ in sweet sorghum under Cd treatment.

Moreover, transpiration rate $(\mathrm{E})$ is an important physiological trait that facilitates gas exchange, and shows significant variations among plants. The results indicated that no significant differences in transpiration between control plant and Cd-treated plants in both cultivars. It ranged from $1.23 \mathrm{mmol}$ $\mathrm{H}_{2} \mathrm{O} / \mathrm{m}^{2} / \mathrm{s}$ to $1.65 \mathrm{mmol} \mathrm{H}_{2} \mathrm{O} / \mathrm{m}^{2} / \mathrm{s}$ in $\mathrm{KE}$, and from 0.42 $\mathrm{mmol} \mathrm{H}_{2} \mathrm{O} / \mathrm{m}^{2} / \mathrm{s}$ to $0.66 \mathrm{mmol} \mathrm{H}_{2} \mathrm{O} / \mathrm{m}^{2} / \mathrm{s}$ in ET (Fig. 2b).

There was no significant difference between stomatal conductance of the two treatments of both cultivars. The highest value of gs (88.69 mmol $\mathrm{CO}_{2} / \mathrm{m}^{2} / \mathrm{s}$ ) was observed in the leaf of $\mathrm{KE}$ control plant, while the lowest $\left(33.08 \mathrm{mmol} \mathrm{CO}_{2} / \mathrm{m}^{2} / \mathrm{s}\right)$ was present at the leaf of ET Cd-treated plant (Fig. 2c). Hence, the stomata conductance was not sensitive to $\mathrm{Cd}$. Although $\mathrm{Cd}$ had no significant effects on stomata conductance, it causes slight decline in the value of gs in all observed leaves. The decrease of stomata conductance in Cd-treated plants was accompanied by a decline of net photosynthesis rate. These results are consistent with the previous study [19].

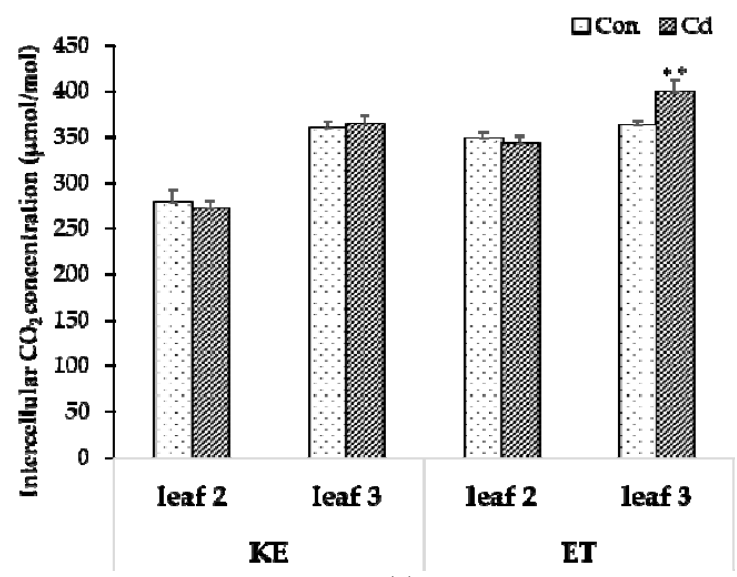

(a)

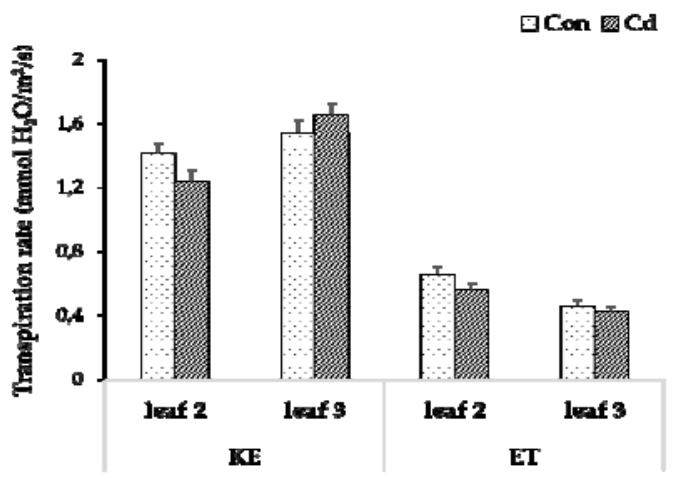

(b)

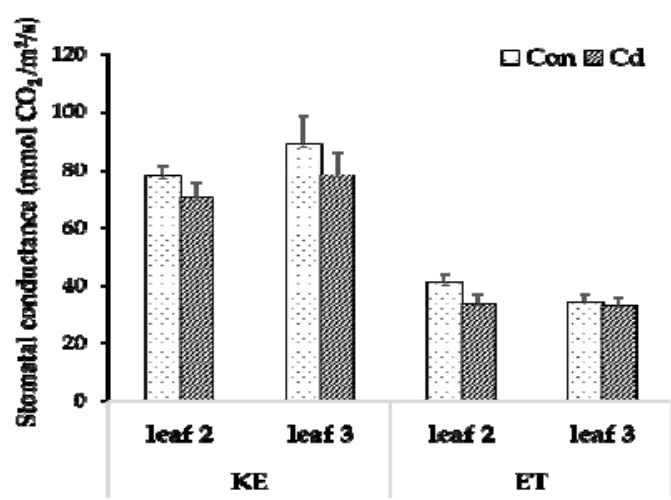

(c)

Fig. 2 Intercellular $\mathrm{CO}_{2}$ concentration (a), transpiration rate (b) and stomatal conductance (c) of KE and ET under the $\mathrm{Cd}$ stress condition.

Data with $* *$ on the column mean significant difference at 0.05 level. 


\subsection{Photosynthesis Pigment: Chlorophyll}

The results of this study showed that chlorophyll content in $\mathrm{KE}$ and $\mathrm{ET}$ were different in response to $\mathrm{Cd}$ stress. Chlorophyll content of KE was enhanced by $\mathrm{Cd}$ stress, but not in ET (Fig. 3). In ET, compare to the control, reductions of chlorophyll a and chlorophyll $b$ were both detected under the $\mathrm{Cd}$ concentration of 100 $\mathrm{mg} / \mathrm{kg}$, although there was no significant difference. Chlorophyll content decreased from $5.74 \mathrm{mg} / \mathrm{g}$ fresh weight (FW) to $5.4 \mathrm{mg} / \mathrm{g} \mathrm{FW}$.

In contrast to that of ET, chlorophyll content of $\mathrm{KE}$ was significantly enhanced by $\mathrm{Cd}$ stress. An increase in the content of total chlorophyll, chlorophyll a and chlorophyll b were detected after treatment with $\mathrm{Cd}$. Chlorophyll concentration increased from $5.08 \mathrm{mg} / \mathrm{g}$ $\mathrm{FW}$ in control plants to $6.43 \mathrm{mg} / \mathrm{g} \mathrm{FW}$ in $\mathrm{Cd}$ plants (Table 1).

In the case of ET, the results also suggest that the reduced rate of photosynthesis might be correlated with chlorophyll content. Similar with the previous studies by Zhu et al. [20], chlorophyll synthesis was affected by Cd stress. Chlorophyll a decreased greatly, while chlorophyll $b$ did not, this indicates that the influence of $\mathrm{Cd}$ stress on chlorophyll synthesis is mainly manifested by the inhibition of chlorophyll a synthesis [20]. Cd stress on chlorophyll synthesis was positively correlated with $\mathrm{Cd}^{2+}$ concentration of 50 $\mathrm{mg} / \mathrm{kg}$ and $100 \mathrm{mg} / \mathrm{kg}$, and the chlorophyll contents significantly decreased $(P<0.05)$ [9].

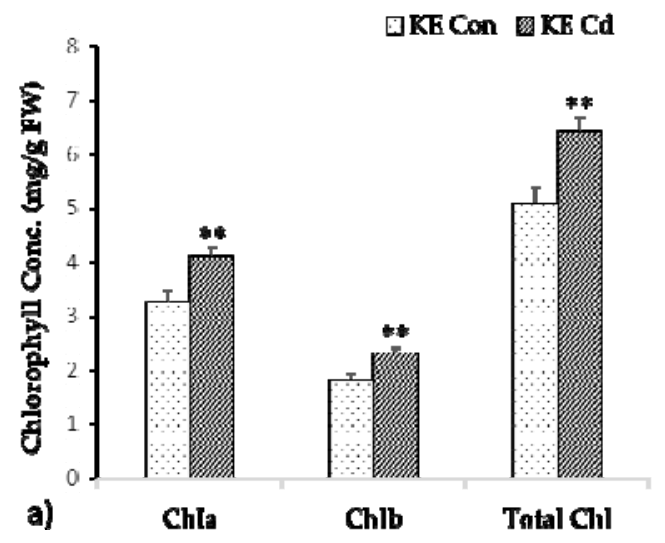

Fig. 3 Chlorophyll concentration in KE (a) and ET (b).
In the case of $\mathrm{KE}$, the result was also consistent with results of Miladinova et al. [21]. There was a slightly increase in the chlorophyll $\mathrm{a}+\mathrm{b}$ content after Cd treatment. The decrease of chlorophyll content in control plants was probably due to leaf senescence during growth. When chlorophyll content was determined, KE control plants were already at the hard dough stage, while the Cd-treated plants just finished the process of granulation and started the soft dough stage.

KE control plants displayed lower chlorophyll concentration and higher $\mathrm{Pn}$, but KE Cd-treated plants inhibited the opposite phenotype (Fig. 3 and Table 1). In this case, the differences in Pn between the two treatments were not caused by the difference in chlorophyll, probably by light reaction system, photosynthesis efficiency or enzyme systems. Heavy metals could react with the photosynthetic apparatus at various levels of organization and display multiple effects on photosynthesis, including interaction with cytosolic enzymes and organics; alteration of the functions of chloroplast membranes, particularly on photosystem I and II, membrane acyl lipids and carrier proteins in vascular tissues; photosynthetic carbon reduction cycle enzymes, xanthophyll cycle and adenylates [22]. Hence, it is necessary to further study the mechanism of $\mathrm{Cd}$ toxic effect on chlorophyll content and photosynthesis response of $\mathrm{KE}$ on a cellular or molecular level.

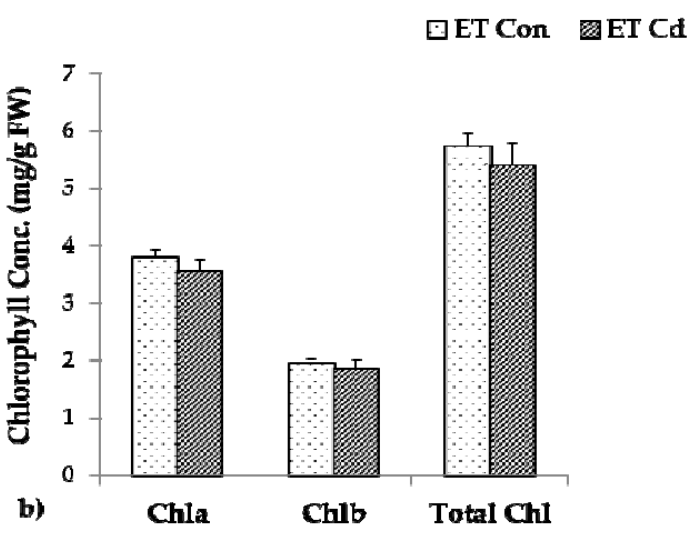

Data with $* *$ on the column means significant difference at 0.05 level. FW: fresh weight. 
Table 1 Chlorophyll concentration (mg/g FW) of KE and ET under the Cd treatment condition.

\begin{tabular}{|c|c|c|c|c|}
\hline Sorghum & & & & IT \\
\hline Chlorophyll & $\mathrm{CK}$ & $\mathrm{Cd}$ & $\overline{\mathrm{CK}}$ & $\mathrm{Cd}$ \\
\hline Chla & $3.27 \pm 0.20^{\mathrm{b}}$ & $4.11 \pm 0.35^{\mathrm{a}}$ & $3.79 \pm 0.35^{\mathrm{a}}$ & $3.55 \pm 0.53^{\mathrm{a}}$ \\
\hline Chlb & $1.81 \pm 0.12^{\mathrm{b}}$ & $2.32 \pm 0.19^{\mathrm{a}}$ & $1.95 \pm 0.19^{\mathrm{a}}$ & $1.85 \pm 0.39^{\mathrm{a}}$ \\
\hline Total Chl & $5.08 \pm 0.32^{b}$ & $6.43 \pm 0.54^{\mathrm{a}}$ & $5.74 \pm 0.54^{\mathrm{a}}$ & $5.40 \pm 0.89^{\mathrm{a}}$ \\
\hline
\end{tabular}

Data with different letters in the same row of a cultivar mean significant difference at 0.05 level.

\section{Conclusions}

According to the results, although there was not significantly different in a few parameters, but generally $\mathrm{Cd}$ damaged the photosynthetic activity of ET via the inhibition of chlorophyll content, intercellular $\mathrm{CO}_{2}$ concentration, transpiration rate, stomatal conductance and especially the decline of photosynthetic rate. Hence, the resistance of $\mathrm{KE}$ in photosynthesis activity to $\mathrm{Cd}$ is greater than that of ET. $\mathrm{KE}$ with all the advantages could become a good candidate for combining phytoremediation and biofuel production.

\section{Acknowledgments}

The authors are grateful to the Research Center of Bioenergy and Bioremediation, College of Resources and Environment (Southwest University, China) for funding the research.

\section{References}

[1] Garbisu, C., and Alkorta, I. 2003. "Basic Concepts on Heavy Metal Soil Bioremediation." Eur. J. Min. Proc. \& Environ. Protect. 3 (1): 58-66.

[2] Halim, M., Conte, P., and Piccolo, A. 2003. "Potential Availability of Heavy Metals to Phytoextraction from Contaminated Soils Induced by Exogenous Humic Substances." Chemosphere 52 (1): 265-75.

[3] Etim, E. E. 2012. "Phytoremediation and Its Mechanisms: A Review." International Journal of Environment and Bioenergy 2 (3): 120-36.

[4] Salt, D. E., Smith, R. D., and Raskin, I. 1998. "Phytoremediation." Annu. Rev. of Plant Physiology and Plant Molecular Biology 49: 643-68.

[5] Zheng, L. Y., Guo, X. S., He, B., Sun, L. J., Peng, Y., Dong, S. S., Liu, T. F., Jiang, S. Y., Srinivasan, R. C., Liu, C. M., and Jing, H. C. 2011. "Genome-Wide Patterns of Genetic Variation in Sweet and Grain Sorghum (Sorghum bicolor)." Genome Biology 12: R114.
[6] Soudek, P., Jakub, N., Lukas, P., and Petrova, S. 2013. "The Sorghum Plants Utilization for Accumulation of Heavy Metals." In Proceedings of the 3rd International Conference on Energy and Environmental Science (ICEES 2013).

[7] Pinto, A. P., Varennes, A., Goncalves, M. L. S., and Mota, A. M. 2006. "Sorghum Detoxification Mechanisms." Journal Plant Nutrition 29 (7): 1229-42.

[8] Zhuang, P., Shu, W. S., Liao, Z. L., Li, B., and Shao, J. S. 2009. "Removal of Metals by Sorghum Plants from Contaminated Land." Journal of Environmental Sciences 21 (10): 1432-7.

[9] Liu, D. L., Hu, K. Q., Ma, J. J., Qiu, W. W., Wang, X. P., and Zhang, S. P. 2011. "Effects of Cadmium on the Growth and Physiological Characteristics of Sorghum Plants." African Journal of Biotechnology 10 (70): 15770-6.

[10] Xie, T. T., Su, P. X., and Shan, L. S. 2010. "Photosynthetic Characteristics and Water Use Efficiency of Sweet Sorghum under Different Watering Regimes." Pak. J. Bot. 42 (6): 3981-94.

[11] Sultana, N., Ikeda, T., and Kashem, M. A. 2001. "Effect of Foliar Spray of Nutrient Solutions on Photosynthesis, Dry Matter Accumulation and Yield in Seawater-Stressed Rice.” Environ. Exp. Bot. 46 (2): 129-40.

[12] Lichtenthaler, H. K., and Wellburn, A. R. 1983. "Determination of Total Carotenoids and Chlorophylls a and b of Leaf in Different Solvents." Biol. Soc. Trans. 11 (5): 591-2.

[13] Borras, L., Maddonni, G. A., and Otegui, M. E. 2003. "Leaf Senescence in Maize Hybrids: Plant Population, Row Spacing and Kernel Set Effects." Field Crops Research 82 (1): 13-26.

[14] Falqueto, A. R., Casso, D., Junior, A. M., Oliveria, A. C., and Bacarin, M. A. 2009. "Physiological Analysis of Leaf Senescence of Two Rice Cultivars with Different Yield Potential.” Pesq. Agropec. Bras. 44 (7): 695-700.

[15] Guo, D. P., Guo, Y. P., Zhao, J. P., Liu, H., Peng, Y., Wang, Q. M., Chen, J. S., and Rao, G. Z. 2005. "Photosynthetic Rate and Chlorophyll Fluorescence in Leaves of Stem Mustard (Brassica juncea var. tsatsai) after Turnip Mosaic Virus Infection.” Plant Science 168 (1): 57-63.

[16] Gulias, J., Flexas, J., Mus, M., Cifre, J., Lefi, E., and 
Medrano, H. 2003. "Relationship between Maximum Leaf Photosynthesis, Nitrogen Content and Specific Leaf Area in Balearic Endemic and Non-endemic Mediterranean Species.” Annals of Botany 92 (2): 215-22.

[17] Reich, P. B., Ellsworth, D. S., and Walters, M. B. 1998. "Left Structure (Specific Leaf Area) Modulates Photosynthesis-Nitrogen Relations: Evidence from Within and Across Species and Functional Groups." Functional Ecology 12 (6): 948-58.

[18] Channappagoudar, B. B., Biradar, N. R., Patil, J. B., and Hiremath, S. M. 2007. "Study on Morpho-Physiological, Biophysical Characters and Alcohol Production in Sweet Sorghum Genotypes." Karnataka J. Agric. Sci. 20 (2): 234-7.
[19] Chen, X., Wang, J., Shi, Y., Zhao, M. Q., and Chi, G. Y. 2011. "Effects of Cadmium on Growth and Photosynthetic Activities in Pakchoi and Mustard." Botanical Studies 52: 41-6.

[20] Zhu, J. L., Xu, Z. F., Cao, H. L., and Ye, W. H. 2008. "Effect of Cadmium on Photosynthetic Traits in Wedelia Trilobata." Ecol. Environ. 17 (2): 657-60.

[21] Miladinova, K., Markovska, Y., Tzvetkova, N., Geneva, M., and Georgieva, T. 2014. "Photosynthesis and Growth Response of Two Paulownia Hybrid Lines to Heavy Metals Cd, Pb and Zn.” Silva Balcanica 15 (1): 83-99.

[22] Prasad, M. N. V., and Strzalka, K. 1999. "Impact of Heavy Metals on Photosynthesis." In Heavy Metal Stress in Plants. Heidelberg, Berlin: Springer Publisher, 117-38. 